\title{
TRADUÇÃO NO ENSINO-APRENDIZAGEM DA SEGUNDA LÍNGUA
}

\author{
TRANSLATION IN LEARNING AND TEACHING SECOND LANGUAGE
}

https://orcid.org/0000-0001-5090-599X Renata Beatriz Freitas Estanislau ${ }^{A}$

${ }^{\text {A }}$ Centro Federal de Educação Tecnológica de Minas Gerais (CEFET-MG), Belo Horizonte, MG, Brasil

Recebido em: 23 abr. 2021 |Aceito em: 6 jul. 2021 Correspondência: Renata beatriz Freitas Estanislau (renatabfe@ hotmail.com)

\section{Resumo}

A metodologia descreve a forma de abordagem de um trabalho. O grammar-translation é uma dessas abordagens para o ensino de idiomas. $\mathrm{O}$ foco desse método repousa na tradução de textos literários, permitindo que os aprendizes comparassem os dois idiomas. Entretanto, com as novas organizações da sociedade, outras abordagens de ensino foram surgindo. Atualmente, uma metodologia que preza pela tradução e comparação entre dois idiomas é vista pelos docentes como prejudicial para o aprendizado. Contudo, a tradução pode ser uma ferramenta útil e eficaz para o processo de ensino-aprendizado. O presente artigo é um debate acerca das características da tradução e como ela pode ser utilizada em sala de aula.

Palavras-chave: tradução; ensino; aprendizado; metodologia; inglês.

\begin{abstract}
Methodology is an approach. The grammar-translation method is one of these approaches for language teaching. The focus of this method relies on the translation of literary texts, allowing learner to compare both languages. Within new society organization, other teaching methods started to be developed. In currently society, a methodology that involves translation and comparisons between two languages can be considered harmful to learning. Nevertheless, translation can be useful and efficient to the teaching-learning process. The following article is a debate concerning translation's main characteristics and how it can be used in classroom.
\end{abstract}

Keywords: translation; learning; teaching; methodology; English. 


\section{Introdução}

Aprender um novo idioma é um processo individual, alguns percorrem o trajeto com mais tranquilidade, enquanto outros passam por turbulências. Entretanto, muito além de aptidão para esse tipo de estudo, é preciso considerar os diferentes motivos que levam ao aprendizado em si. Quando chegamos à decisão de falar um novo idioma, somos guiados por necessidades e gostos distintos; há quem aprenda por hobby, mas há quem tenha o segundo idioma como exigência. Mas, por que isso é importante quando se trata de metodologia de ensino?

Quando pensamos em metodologia, consideramos os diferentes meios que podemos utilizar para alcançar um determinado um objetivo, por isso, ela pode ser entendida como um conjunto de abordagens, ou métodos. Logo, os métodos sofrem variações segundo as demandas sociais. Atualmente, grande parte dos discentes que procuram escolas e professores para a aprendizagem de um segundo idioma o fazem por urgência; o mundo globalizado atual demanda capacidade comunicativa com diferentes pessoas e culturas. E é diante desse cenário interligado que o inglês assume o papel de "língua franca" e torna-se um idioma falado por nativos e estrangeiros.

Pela necessidade comunicativa, a principal habilidade de aprendizado passa a ser a fala, speaking. Contudo, essa premissa não era comum há alguns séculos atrás. Anteriormente, a comunicação era, majoritariamente, feita pelo texto escrito. Além disso, as obras literárias não eram amplamente traduzidas, lia-se o texto original transcrito, e não a sua tradução. Assim, para esse modelo de sociedade, quando se pensava em aprender um idioma valorizava-se o texto e as regras gramaticais.

Temos, então, duas sociedades distantes no tempo com a mesma necessidade: usar um idioma que não seja nativo. Será que o método de ensino seria o mesmo para elas? Em um contexto que privilegia a fala, métodos focados na escuta e repetição são mais propagados e utilizados, pois priorizam a comunicação. Já quando há maior preocupação com o texto, metodologias de tradução e comparação gramaticais são mais comuns.

O método grammar-translation foi muito utilizada no ensino de língua estrangeira como uma herança do ensino das chamadas línguas mortas - idiomas que pela falta de falantes ficam parados no tempo-espaço, não há evoluções linguísticas e sua gramática não sofre modificações. Sem alterações, a língua passa a ser aprendida e ensinada apenas por meio da tradução comparativa. Segundo Scott Thornbury (2017) o grammar-translation foi originalmente pensado para crianças do século XIX que, diante da pouca idade, não seriam 
capazes de ler textos clássicos, então, utilizava-se textos cotidianos para serem traduzidos e comparados. Em termos práticos, os alunos eram apresentados a frases e léxicos que deveriam ser traduzidos do idioma alvo para a primeira-língua (L1) e vice-versa. A tradução é a principal - se não a única - metodologia. Para Thornbury (2017), trata-se de uma metodologia sem método. O foco está na gramática e na capacidade do aluno de memorizar as regras.

Trazendo essa abordagem para a sociedade atual, que prioriza a comunicação ao invés do texto, será essa uma escolha de aprendizado? Em um texto para Cambridge University Press, Philip Kerr (2019) demonstra que o uso da L1 em salas de aula é amplamente evitado pelos docentes. Por isso, o método de grammar-translation é igualmente renegado. Mas será que a tradução sempre irá desempenhar um papel negativo no processo de aprendizado?

Objetivando compreender a influência da tradução no processo de aquisição de uma língua estrangeira dividimos o artigo em dois momentos: tradução e tradução no aprendizado. É importante ressaltar que nosso artigo terá como foco o ensino-aprendizagem da língua inglesa, entretanto, acreditamos que o processo apresenta características independentes do idioma. Dito isso, ainda que direcionado para o inglês, propomos um estudo que pode ser aplicado em diferentes línguas.

No nosso primeiro tópico teremos como referencial teórico Rosemary Arrojo (1999), Roman Jakobson (1985) e Paul Ricoeur (2011); nosso arcabouço visa discutir os aspectos linguísticos e interpretativos da tradução. No segundo tópico, debateremos como a tradução pode ser utilizada no contexto da educação, considerando os atuais objetivos de aprendizagem da língua estrangeira. Como suporte teórico, traremos escritos de Graham Hall \& Guy Cook (2012), além dos já citados Scott Thornbury (2017) e Philip Kerr (2019). Nosso propósito é mostrar como a tradução, associada a outros fatores e usada de maneira mais prática, pode ser eficaz para a aprendizagem de um novo idioma.

O principal objetivo do nosso estudo é teorizar sobre as influências da tradução na aquisição de uma segunda língua, quebrando o mito que há em torno da má influência da língua nativa no processo de ensino-aprendizado. Acreditamos que tal discussão é importante para o contexto atual por vivermos em uma sociedade plural em sentido social, cultural e, consequentemente, linguístico. A aprendizagem de um novo idioma não deve sobrepor a língua nativa; um conhecimento deve complementar o outro, e é essa percepção que visamos difundir.

\section{Tradução}

Revista Interinstitucional Artes de Educar. Rio de Janeiro, V.7, N.2 - pág. 1264-1277 mai-ago de 2021: "Dossiê História das Mulheres e Educação”-DOI: 10.12957/riae.2021.63465 
A tradução acontece todos os dias e a todo momento, pois ela não se restringe a uma transposição entre línguas. Para definir o que é tradução, é preciso ter em mente o seu principal objetivo, e esse, segundo Rosemary Arrojo (1999) “[...] é que todos os componentes significativos do original alcancem a língua-alvo de tal forma que possam ser usados por seus receptores.” (p.12). Logo, a tradução carrega em seu cerne uma função comunicativa, papel exercido antes mesmo da sua estruturação teórica e da criação dos cursos de graduação sobre o tema. O homem sempre precisou da tradução para se comunicar. Resultante de uma necessidade, a tradução hoje se organiza em diferentes teorias e abordagens, principalmente no âmbito literário. Isso porque é na literatura escrita que a língua alcança o seu ápice de sistematização e esbarra em conceitos de autoria e originalidade. Pensar tradução implica em conhecer um multiverso em que diferentes aspectos linguísticos e semânticos se relacionam.

No campo linguístico, sabemos que a representação da língua em texto é feita a partir dos morfemas escritos. E que a associação que fazemos entre palavra e sentido é definida por Ferdinand Saussure (2006) como signo linguístico, uma junção do significante e do significado, realizada de maneira arbitrária, ou seja, "O signo linguístico une não uma coisa e uma palavra, mas um conceito e uma imagem acústica." (SAUSSURE, 2006. p.80). Diante dessa construção linguística, Roman Jakobson (1970) propõe que a própria associação entre o sentido e a palavra - seja ela escrita ou falada - também é uma tradução. Uma tradução da realidade para uma representação grafada ou sonora. É nessa perspectiva, que Jakobson (1970) expande a tradução em três vertentes: intralingual, inter-semiótica e interlingual. A primeira delas é a tradução dentro do mesmo idioma, alterando apenas o signo verbal; por exemplo, "O termo "solteiro" pode ser convertido numa designação mais explicita, "homem não-casado", sempre que maior clareza for requerida." (JAKOBSON, 1970, p.64). O "parafrasear" uma palavra, frase ou texto é visto como ato tradutório em Jakobson. A tradução inter-semiótica, assim como a anterior, permanece nos limites do mesmo idioma, mas apresenta uma mudança no seu veículo de produção, por exemplo, quando uma poesia se torna música, ela sofre um processo de tradução de gênero, o mesmo acontece quando um livro é transformado em filme. Quando se trata da tradução de um idioma para outro, Jakobson identifica o processo como “interlingual”, aqui há a mudança completa dos signos linguísticos, e também da sintaxe. É nesse tipo de tradução que reside as maiores problemáticas sobre o tema.

A tradução interlingual - ou tradução propriamente dita, como também chama Jakobson (1970) - é paradoxal porque coloca dois idiomas, com sintaxes e semânticas distintas em uma posição comparativa. A partir dessa comparação chega-se à conclusão de que não há 
uma relação direta entre elas, mas sim uma equivalência. Logo, a tradução jamais será o original, assim como o original não será a tradução, mas, ainda assim, os textos serão tidos como dependentes e a tradução irá se submeter ao original. Contudo, as diferenças entre eles serão inevitáveis, e o sentimento de ler o original será frustrado para aqueles que conhecem a complexidade do processo. "Esse paradoxo concerne efetivamente a uma problemática sem igual, sancionada duplamente por um voto de fidelidade e por uma suspeita de traição." (RICOEUR, 2011. p. 22). A questão da fidelidade é uma das principais dicotomias do processo, o que Friedrich Schleiermacher (2001) expressou com duas alternativas: ou o tradutor leva o autor até o leitor, ou leva o leitor até o autor.

Quando pensamos em "levar o leitor até o autor", a tradução se aproxima mais do original e chega ao leitor com estranheza. Logo, o texto não é fluido e ainda que mensagem seja transmitida, referências culturais podem perder o sentido e a nova língua rejeitará o ritmo estrangeiro do texto. Mas, se o tradutor buscar "levar o autor até o texto", a tradução se afasta da linguagem do original, e se aproxima do seu leitor e, ao fazer isso, é "domesticado" e o sentido é mais claro. Quando o texto é pensado para se adequar à língua, o leitor estrangeiro tem a impressão de ler o original e a tradução se torna "invisível".

A invisibilidade da tradução alimenta a percepção de que existe uma tradução perfeita. Contudo, “[...] não existe critério absoluto de boa tradução. Para que se pudesse dispor de tal critério seria preciso poder comparar o texto de partida e o texto de chegada a um terceiro texto portado de sentido idêntico àquele que se supõe circular do primeiro ao segundo" (RICOUEUR, 2011, p.46). Logo, o mito da tradução perfeita precisa ser debatido e posto ao fim. Podem existir discordância entre o que se entende como a melhor tradução para um texto, assim como cada um pode ter um gosto pessoal para uma determinada abordagem. Mas, o único fator que pode ser levado em consideração do que seria uma "boa tradução" está na relação de equivalência com o original. A percepção da equivalência pode ser diferente segundo a teoria que se segue.

Walter Benjamin (2008), no texto "A tarefa-renúncia do tradutor", faz um estudo crítico filosófico para definir a tradução e identificar qual a função do tradutor. Uma das conclusões que temos a partir de Benjamin (2008) é que a tradução não é uma cópia do seu original, mas uma forma. Como forma, a tradução revela a relação existente entre duas línguas diferentes, expondo a essência do texto. Em Benjamin (2008), a tradução é um processo de purificação do texto que permite que o escrito se renove e se modifique a cada nova releitura, e com isso revelar o real objetivo, ou seja, a sua essência. Com isso, a tradução é uma das formas do texto original, e é por meio delas que "[...] a vida do original, alcança, de maneira 
constantemente renovada, seu mais tardio e vasto desdobramento." (BENJAMIN, 2008, p.69). Essa renovação do original apontada por Benjamin só é possível porque ele parte do pressuposto que todas as línguas são complementares, não apenas no seu sentido sintático, mas também por se relacionarem a uma mesma ideia de texto. Na abordagem benjaminiana a tradução não deve ser literal nem no âmbito linguístico e nem na ideia do texto, "A verdadeira tradução é transparente, não encobre o original, não o tira da luz; ela faz com que a pura língua, como que fortalecida por seu próprio meio, recaia ainda mais inteiramente sobre o original." (BENJAMIN, 2008, p.78). Logo, o texto traduzido deve ser construído no novo idioma como foi no original, assim haverá fragmentos comuns em ambas as versões.

Em uma perspectiva intermediária, ou seja, em defesa de uma tradução que não seja nem totalmente afastada do original, e nem em busca de uma cópia fiel, Jose Paulo Paes (1990) propõe a congenialidade da tradução. Paes não coloca o tradutor em posição igual ou superior ao autor, e isso resulta em uma valorização da tradução segundo a sua realidade: uma recriação comedida, submissa ao original, mas consciente da sua tarefa impossível de transpor o mesmo texto. "O fundamento da congenilaidade está em que o recriado repete numa segunda instância, a tradutória, o mesmo gesto feito pelo poeta na primeira instância, a criativa." (PAES, 1990, p.46). Se seguirmos a linha teórica de Paes, chegamos a um meio termo da abordagem, não há a aproximação linguística acima do sentido e nem a recriação completa da linguagem. A primeira conclusão a que podemos chegar é que a tradução de um texto segue diferentes abordagens, e não podemos determinar qual a mais correta, contudo, um texto traduzido a partir de uma linha de estudo, deve se manter no mesmo caminho até o final. "Certamente, desse contraste esclarece-se logo o quão diferente deve ser o procedimento em todos os detalhes e como tudo seria incompreensível e impróspero se quisesse trocar de método no mesmo trabalho." (SCHLEIERMACHER, 2001, p.24)

Até aqui podemos perceber que definir um único sentido para a tradução não é uma tarefa fácil, existem variáveis e diferentes propostas de estudos. Abordar a teoria é importante para compreender a amplitude do termo e compreender por que o aprendizado de um idioma a partir de uma técnica baseada em tradução pode ser complexo. Entretanto, ainda que tendo início em diferentes pontos de como fazer tradução, todos os teóricos concordam que não é possível reproduzir uma fala, texto ou ideia em idiomas distintos sem que haja alteração. E é nessa diferença que a crítica em torno do método de gramar-translation respalda o argumento de que a tradução pode prejudicar o aprendiz, já que nem todos os termos e regras terão correspondentes gramaticais equivalentes. Sobre essas diferenças, Jakobson (1970) diz que "A 
ausência de certos processos gramaticais na linguagem para a qual se traduz nunca impossibilita uma tradução literal da totalidade da informação conceitual contida no original." (p.67). Logo, tudo o que se diz em uma língua, é possível dizer em outra.

As diferenças de sintaxe e semântica são conhecidas pelos tradutores e, ainda assim, a tradução existe e é efetiva. Essa possibilidade é possível a partir da contextualização da ideia da mensagem, "quanto mais rico for o contexto de uma mensagem, mais limitada será a perda de informação." (JAKOBSON, 1970, p.69). Com esse pressuposto, o uso da tradução deve ocorrer a partir de um contexto, e isso se aplica não somente ao texto literário, mas também a traduções interlinguais cotidianas, inclusive do aprendiz. É sempre importante ter em mente que uma língua é um reflexo de uma cultura, sua gramática e léxico são uma representação de um modo de vida de um povo. $\mathrm{O}$ uso da tradução no processo de ensino-aprendizado não pode ocorrer isolado do seu uso real; o professor não pode restringir o idioma em suas regras de sintaxe, "é por isso que uma série de traduções sucessivas de uma mesma frase isolada, [...] poderia acabar privando completamente tal mensagem de seu conteúdo original." (JAKOBSON, 1970, p.69).

Dessa forma, a tradução não é uma reprodução exata e ela só existe a partir de um contexto, além disso, não é única. A tradução é uma perspectiva do texto, uma interpretação. Stanley Fish (1980) entende que o texto não é uma evidência interpretativa, mas sim uma consequência, isso quer dizer que texto, interpretação e contexto não são fatores que emergem um após o outro, mas são construídos juntos. Compreender essa função permite que o discente, ao usar a técnica de tradução na aprendizagem, entenda que não se pode isolar a frase e traduzila, é preciso inseri-la em um contexto e questionar o seu objetivo. Jakobson (1970) diz que a linguagem em seu papel cognitivo depende mais das operações metalinguísticas do que do seu sistema gramatical, pois a interpretação é uma recodificação, logo, uma tradução. Permitir que os alunos façam conexões de um idioma com outro é uma forma de atribuir a metalinguagem ao aprendizado, expandindo as conexões entre os idiomas e associando o contexto, ao objetivo e a gramática. E como podemos aplicar a contexto, interpretação e tradução no aprendizado? Isso é que destacaremos no próximo tópico.

\section{Tradução no aprendizado}

Até o presente momento, nosso debate nos mostrou que a tradução é uma forma de resistência linguística, mesmo diante de fatores adversos, ela existe e se mostra necessária. Traduzir é um ato revolucionário e interpretativo, exige conhecimento linguístico, mas também 
demanda uma percepção cultural da língua, uma leitura interpretativa e uma noção de estilo. Contudo, a tradução não se restringe ao texto, como também foi posto anteriormente, ela participa de diferentes esferas sociais e contextuais, incluindo a sala de aula.

No contexto de aquisição de uma segunda língua, a dicotomia da tradução sai do campo da fidelidade ao original e começa a questionar a sua eficácia no processo de aprendizagem. Philip Kerr (2019) assim como Graham Hall \& Guy Cook (2012) citam pesquisas autorais e de outros pesquisadores que, ao questionarem professores quanto ao uso da primeira língua para o ensino, percebem o sentimento de culpa do uso da tradução na sala de aula por medo das consequências no processo de aprendizagem. Essa percepção, em nossa interpretação, representa uma materialização de uma perspectiva mitológica de que se aprende inglês apenas por meio de si próprio e que o uso de qualquer outro idioma será prejudicial para a aquisição da nova língua. Esse posicionamento, segundo Kerr (2019), é uma crença que “[...] pode ser identificada desde o início do século $\mathrm{XX}$, quando ocorreu o rápido crescimento de escolas de idiomas privadas para adultos que queriam aprender um idioma por motivos práticos, ao invés de acadêmicos",i (p. 2, tradução nossa).

Logo, vivemos um momento de mudança de paradigma em relação ao processo de ensino de idiomas. Hall \& Cook (2012) postulam que essa nova percepção é resultado das transformações em torno do meio acadêmico e político da área, além disso, os aprendizes são cada vez mais caracterizados como usuários de múltiplas línguas; o cenário multicultural contemporâneo começa a refletir nas metodologias de ensino. Com o inglês avançando como língua-franca os aprendizes começam a promover uma nova percepção do idioma. Nesta nova forma de identificação, o inglês deixa de ser comparado com aquele do indivíduo nativo e passa a ser percebido como um meio de comunicação. Ao desassociar o idioma do seu contexto cultural, o padrão a ser alcançado não é mais um padrão nativo, ou seja, o aprendiz não sente a necessidade de ser "aprovado" pelo "falante original", por isso, preocupações com a exatidão da pronúncia, termos ou concordâncias gramaticais são colocados em segundo plano, dando uma maior ênfase ao fator comunicativo da língua. Com essa nova percepção do inglês, uma abordagem de ensino monolíngue é cada vez mais refutada pelos aprendizes.

Em uma noção de ensino monolíngue, professores alegam que quanto maior a exposição do aluno ao novo idioma, mais rápida e eficaz será a sua aprendizagem. A premissa parte do pressuposto que, mesmo sem entender, o aluno precisa de input, ou seja, incentivos externos para manifestar e aprender o novo idioma. Contudo, a pesquisa de Jan Ho Lee (2012) aponta que quando o aluno é exposto ao idioma, mas não consegue compreender o que se diz, 
a tendência é que esse discente não aprenda e nem seja estimulado. Na verdade, quando não compreendido, o chamado input pode ser prejudicial, pois, ao não conseguir se comunicar, o indivíduo se frustra e não consegue absorver e nem expressar a nova língua. Lee (2012) entrevistou jovens alunos coreanos aprendizes de inglês para compreender como eles se relacionam com ensinos monolíngues e uma das conclusões é que, na perspectiva dos alunos, uma abordagem centralizada no inglês é mais efetiva para alunos com conhecimento avançado. Isso acontece porque quanto maior a percepção do aluno, mais ele consegue compreender e interpretar. Entretanto, nos níveis iniciais, a percentagem de tradução e comparação com a primeira língua é muito maior, pois nessas classes os alunos têm mais dificuldade de compreender enunciados e ainda estão se acostumando ao novo sistema linguístico.

A verdade é que, independentemente do posicionamento do professor, o segundo idioma será adquirido por meio da tradução. Segundo Hall \& Cook (2012), “[...] aprender uma segunda língua não é o mesmo que a aquisição da primeira língua, uma vez que a própria língua do aprendiz tem papel central no desenvolvimento e uso do novo idioma." (p.281, tradução nossa $)^{\text {ii }}$. Logo, a aquisição do primeiro idioma faz parte de um processo que Noam Chomsky (1928) coloca como sendo um conhecimento adquirido sem treinamento específico e com pouco esforço, a aquisição de um segundo, ao contrário, exige empenho e comparação ao primeiro. Essa "comparação" apontada por Chomsky é o que aqui chamamos de "tradução", e o que Hall \& Cook (2012) chamam de "língua própria do aprendiz" iii. Por mais que as terminologias sejam diferentes, a proposta é semelhante: o aprendiz usa o conhecimento da primeira língua para aquisição do novo idioma, e isso é feito por meio da tradução e da comparação.

Nessa perspectiva, compactuamos com a ideia de uma Gramática Universal, proposta por Chomsky (1928).

Definamos "gramática universal" (GU) como o sistema de princípios, condições e regras que são elementos ou propriedades de todas as línguas humanas, não por mero acaso, mas por necessidade - quero dizer, é claro, necessidade biológica, e não lógica" (CHOMSKY, 1928, p.28).

Dessa forma, somos programados, biologicamente, para aprender um idioma; e, por mais que exista uma infinidade deles no mundo, todos estão limitados e conectados por um propósito comum, uma lógica biológica que nos permite aproximá-los e compará-los. E, colocando duas línguas distintas na posição comparativa - como em uma tradução percebemos as diferenças gramaticais e semânticas, mas a língua não existe fora de um contexto, assim como a tradução. É nesse sentido que afirmamos que "Dominar uma língua 
está relacionado ao contexto cognitivo do indivíduo que é, sem dúvidas, influenciado pela cultura e personalidade dele ou dela; isso também acontece na relação de ensino-aprendizagem da segunda língua." (GAMAGE, 2020, p.2) .

A partir da teoria de Chomsky (1928) temos uma estrutura básica comum as línguas que comprova a necessidade - e a naturalidade - com que traduzimos de um idioma para outro enquanto aprendemos uma nova língua. Essa comparação permite que as sutilezas do idioma alvo sejam identificadas e compreendidas, permitindo que o aprendiz tenha um processo de aprendizado mais autônomo e consciente.

Dar autonomia de aprendizado para o aluno é dar a ele uma nova função; é colocar em suas mãos o conhecimento e identificá-lo como um usuário da língua, e não como um aprendiz. Essa mudança de atitude permite que o professor veja a tradução como ferramenta para auxiliar no processo de aprendizagem. A possibilidade de comparar e analisar dois idiomas distintos expande as fronteiras do conhecimento não somente na sintaxe e na semântica. Além disso, permite que o aluno acesse entendimentos linguísticos já adquiridos com a primeira língua, engajando e usando noções prévias para a construção de novas ligações.

Os benefícios de um ensino-aprendizado colaborativo e comparativo permitem uma maior participação e autonomia dos alunos. Porém, não podemos perder de vista o objetivo principal: o ensino de um idioma. A aprendizagem vem da observação, autonomia, conhecimento, contato, mas também, da prática. Se começarmos a utilizar a primeira língua em sala de aula, como medir o desempenho do aluno no idioma alvo? Nesse sentido, Hall \& Cook (2012) apontam a necessidade da criação de um ambiente que estimule o uso da língua estrangeira de forma natural. O objetivo aqui é desenvolver uma atitude de equilíbrio em relação ao uso dos dois idiomas; o professor não deve ignorar o conhecimento linguístico prévio do aluno só porque ele não está na língua alvo, pois, como vimos anteriormente, há um ponto comum entre todos os idiomas por meio da gramática universal.

Alcançar tal equilíbrio exige tempo, estudo e uma postura condizente com o objetivo principal. Para isso, é preciso deixar de perceber a tradução - ou a primeira língua - como sendo um ponto prejudicial para o aprendizado. Ter uma atitude positiva em relação ao uso dos dois idiomas levará o professor a compreender a conexão entre as línguas e usar as semelhanças e diferenças em favor do aprendizado. O uso da primeira língua possibilita ligações psicológicas com os alunos, criando um ambiente favorável para o aprendizado. Além disso, poupa tempo de aula ao expor e apontar as particularidades linguísticas do novo idioma. Ao traduzir, o aluno compreende que cada língua tem as suas regras gramaticais, e que a tradução não pode - e nem 
consegue - existir com termos completamente iguais, desencorajando um aprendizado mecânico e estimulando a percepção crítica e interpretativa da língua.

\section{Conclusão}

Aprender é ao mesmo tempo coletivo e individual; no caso dos idiomas, por exemplo, lidamos com a aquisição de um fator cultural. Língua é comunicação e isso se constrói no uso, daí sua característica coletiva. Entretanto, cada aprendiz possui seu próprio ritmo e percebe o idioma com suas próprias regras, principalmente quando advindos de outros países, com línguas distintas. Dominar um segundo idioma exige a união de duas percepções tida como opostas, logo, não há uma única forma de aprender, assim como não podemos afirmar que existe apenas uma maneira de ensinar.

Começamos esse artigo ressaltando que existem diferentes métodos de ensino, cada qual com seus objetivos e meios. O fator social do aprendizado é parte influente no método, e ele também define o que será mais comum. O que vivenciamos hoje é uma preocupação com a comunicação, logo, prioriza-se metodologias que prezam pela fala e escuta. Contudo, esse excesso de atenção à fala leva ao extremo de refutar a presença da primeira língua dos falantes, baseando-se em um posicionamento de que quanto maior a exposição do discente ao idioma alvo, maior será o seu desenvolvimento.

Questionar uma abordagem sem apresentar justificativas claras é uma atitude vaga. No nosso primeiro tópico, quando apresentamos as características da tradução, podemos perceber como o processo é complexo e "invisível”; a tradução desafia as barreiras linguísticas e surge em um contexto inóspito. Assumimos que não há como julgar a qualidade da tradução sem se comprometer a um posicionamento teórico, e concluímos que traduzir sempre será um ato pendular, ora mais próximo ao texto, ora ao leitor.

Essa natureza polivalente da tradução a leva para a sala de aula, e nesse contexto, as preocupações com a fidelidade são substituídas pelos questionamentos quanto a sua eficácia no ensino. O segundo tópico nos permite concluir que a tradução, se usada por si só, se restringe apenas à semântica e à sintaxe, e pode gerar um segundo problema, que é o excesso da primeira língua em sala de aula. Mas, se usada conscientemente, pode ser um caminho facilitador para a internalização do novo idioma. Contudo, para que ela seja benéfica, é preciso uma mudança de postura acerca do seu uso. Por isso, com esse artigo estimulamos um pensamento crítico em torno de posicionamentos de ensino realizados completamente na língua estrangeira. $\mathrm{O}$ que trouxemos aqui foram estudos de outros pesquisadores que comprovam o nosso parecer de que 
ter a primeira língua como ferramenta - e não como vilã - pode ser uma atitude que beneficiará o desenvolvimento do(a) aluno(a).

Para nós, a tradução é uma forma de integração, consideração e acolhimento do aprendiz. Ela é uma via rápida e eficaz que vê no aluno um ser pensante, portador de uma biologia favorável à aquisição de idiomas e que tem capacidade para comparar duas línguas distintas identificando suas semelhanças e diferenças. Cada idioma apresenta uma lógica própria interna, mas todos se assemelham quanto ao seu papel na vida humana. Quando citamos a teoria da gramática universal de Chomsky (1980) nosso objetivo era mostrar a aptidão que os seres humanos possuem para a linguagem, assim, como vimos em Jakobson (1985), sabemos que tudo o que existe e se comunica em uma língua é passível de existir em outra.

Estudar os aspectos teóricos da tradução nos permite compreender como o processo resiste mesmo diante de fatores adversos. Dizer a mesma coisa de maneira diferente exige submissão de texto, mas também amplo conhecimento em dois idiomas. Para o tradutor, uma tarefa solitária, mas para o professor, uma tarefa comunitária. Usar a tradução em sala de aula é apresentar aos alunos o idioma em seu ambiente natural, dentro de contextos, distinguindo entre diferentes objetivos de comunicação e trazendo o aspecto cultural da língua. Criar esse contexto e cativar o aluno a participar é o que Hall \& Cook (2012) definem coma sendo a criação de um ambiente favorável ao aprendizado.

A atitude do professor diante de uma metodologia de ensino que valorize a tradução muito dirá sobre a sua eficácia. Como foi apresentado anteriormente, não podemos perder o foco do nosso principal objetivo, mas ao mesmo tempo, não podemos ignorar o conhecimento prévio dos nossos alunos. Não há, infelizmente, uma receita de como agir ao agregar a tradução, nós, pesquisadores, não podemos ditar regras universais para as salas de aula. O que podemos fazer, e o que almejamos fazer aqui, é propor um novo caminho para os docentes.

Ainda que defensores da tradução em sala de aula, reconhecemos seus limites. A tradução não consegue, sozinha, sanar as necessidades comunicativas da língua. Ela não tem um foco na fala ou na compreensão auditiva. O que a tradução pode oferecer é uma nova percepção linguística; ela auxilia na compreensão das particularidades do idioma e propõe uma visão da sua organização lógica. As leis que regem a língua internamente podem ser aprendidas por meio da comparação ao idioma já internalizado dos alunos. Por mais diferentes que as línguas sejam, há proximidades entre elas, é isso que preza a teoria de Chomsky, o posicionamento do Jakobson e todas as traduções realizadas e publicadas no nosso cotidiano. 
O principal legado que esperamos com esse artigo é a percepção da tradução como uma associação, um trampolim para a expansão linguística. Seguimos com a percepção de que idiomas são complementares, e que nas percepções das diferenças os aprendizes compreendem a natureza única de cada idioma, e nas semelhanças a lógica geral das línguas facilita o aprendizado. A tradução não é a única escolha metodológica, assim como excluir a língua nativa não é o único caminho para o ensino de um idioma estrangeiro.

\section{Referências}

ARROJO, Rosemary. Oficina de tradução: a teoria na prática. São Paulo: Ática, 1999.

BENJAMIN, Walter. A tarefa-renúncia do tradutor. Tradução de Susana Kampff Lages. In:

CASTELLO BRANCO, Lúcia (Org.). A tarefa do tradutor de Walter Benjamin: quatro traduções para o português. Belo Horizonte: FALE/UFMG, 2008. p. 66-81.

CHOMSKY, Noam. Reflexões sobre a linguagem. Tradução de Carlos Vogt, Cláudia Tereza Guimarães de Lemos, Maria Bernadete Abaurre Cnerre, Clarice Sabóia Madureira e Vera Lúcia Maia de Oliveira.São Paulo: Cultrix, 1980.

FISH, Stanley. What makes an interpretation acceptable? In: FISH, Stanley. Is there a text in this class? The authority of interpretive communities. Cambridge: Harvard University Press, 1980. Cap. 15, p. 338-355.

GAMAGE, K. G. Swarnananda. The Pedagogical Application of the Grammar Translation Method as an Effective Instructional Methodology in Teaching English as a Second Language. Oalib, [S.L.], v. 07, n. 11, p. 1-10, 2020. Scientific Research Publishing, Inc.. http://dx.doi.org/10.4236/oalib.1106913.

HALL, Graham; COOK, Guy. Own-language use in language teaching and learning. Language Teaching, [S.L.], v. 45, n. 3, p. 271-308, 15 jun. 2012. Cambridge University Press (CUP). http://dx.doi.org/10.1017/s0261444812000067.

JAKOBSON, Roman. Linguística e comunicação. Tradução de Isidoro Blikstein e José Paulo Paes. 2. ed. São Paulo: Cultrix, 1985.

KERR, Philip. Introduction. Part of the Cambridge Papers in ELT series. Cambridge:

Cambridge University Press, 2019. 
KERR, Philip. The use of L1 in English language teaching. Part of the Cambridge Papers in ELT series. Cambridge: Cambridge University Press, 2019.

LEE, Jang Ho. Reassessment of English-only approach in EFL context in view of young learners' attitudes, language proficiency, and vocabulary knowledge. Multilingual Education, London, v. 2, n. 1, p. 1-11, 15 jun.2012. Springer Science and Business Media LLC

PAES, José Paulo. Sobre a tradução de poesia: alguns lugares-comuns e outros não tanto. In: Tradução a ponte necessária: aspectos e problemas da arte de traduzir. São Paulo:

Ática, 1990. p. 33-48.

RICOEUR, Paul. Sobre a tradução. Tradução de Patrícia Lavelle. Belo Horizonte: Ed.

UFMG, 2011. p. 21-31.

SAUSSURE, Ferdinand. Curso de Lingüística Geral. São Paulo: Cultrix, 2006.

SCHLEIERMACHER, Friedrich et al. Über die verschiedenen Methoden des Übersetzens/Sobre os diferentes métodos de tradução/Sobre os diferentes métodos de traduzir/Dos diferentes métodos de traduzir. Tradução de Margarete von Mühlen Poll. Scientia Traductionis, Florianópolis, n. 9, p. 3-70, 11 jul. 2011. Universidade Federal de Santa Catarina (UFSC). Doi: <http://dx.doi.org/10.5007/1980-4237.2011n9p3>. Disponível em: $<$ https://periodicos.ufsc.br/index.php/scientia/article/view/1980-4237.2011n9p3 >. Acesso em: 25 abr. 2018.

THORNBURY, Scott. 30 language-teaching methods. Great Britain: Cambridge University Press, 2017.

\footnotetext{
i “" [...] can be traced to the beginning of the 20th century when there was a rapid development of private language schools for adults, who wanted to learn a language for practical, rather than academic, reasons." (KERR, 2019, p.2) [TRADUÇÃO NOSSA]

ii “[...] learning a new language cannot be the same as first language acquisition, for the learners' own language plays a central role in the development and use of their new language" (HALL \& COOK, 2012, p.281) [TRADUÇÃO NOSSA]

iii "learners own-language" (HALL \& COOK, 2012) [TRADUÇÃO NOSSA]

iv Mastering a language is related to one's cognitive context which is undoubtedly influenced by his/her culture and personality; this is particularly so in relation to Second Language teaching/learning contexts. (GAMAGE, 2020, p.2) [TRADUÇÃO NOSSA]
} 